\title{
Measurements on pointing error and field of view of Cimel-318 Sun photometers in the scope of AERONET
}

\author{
B. Torres $^{1,2}$, C. Toledano ${ }^{1}$, A. Berjón ${ }^{3}$, D. Fuertes ${ }^{1}$, V. Molina ${ }^{1}$, R. Gonzalez ${ }^{1}$, M. Canini ${ }^{4}$, V. E. Cachorro ${ }^{1}$, P. Goloub ${ }^{2}$, \\ T. Podvin ${ }^{2}$, L. Blarel ${ }^{2}$, O. Dubovik ${ }^{2}$, Y. Bennouna ${ }^{1}$, and A. M. de Frutos ${ }^{1}$ \\ ${ }^{1}$ Group of Atmospheric Optics, Valladolid University, Valladolid, Spain \\ ${ }^{2}$ Laboratoire d'Optique Amosphérique - UMR8518, Université des Sciences et Technologies de Lille, \\ Villeneuve d'Ascq, France \\ ${ }^{3}$ Izana Atmospheric Research Center, Spanish Meteorological Agency, Tenerife, Spain \\ ${ }^{4}$ CIMEL Electronique, Paris, France
}

Correspondence to: B. Torres (benjamin@goa.uva.es)

Received: 23 February 2013 - Published in Atmos. Meas. Tech. Discuss.: 25 March 2013

Revised: 16 July 2013 - Accepted: 17 July 2013 - Published: 30 August 2013

\begin{abstract}
Sensitivity studies indicate that among the diverse error sources of ground-based sky radiometer observations, the pointing error plays an important role in the correct retrieval of aerosol properties. The accurate pointing is specially critical for the characterization of desert dust aerosol. The present work relies on the analysis of two new measurement procedures (cross and matrix) specifically designed for the evaluation of the pointing error in the standard instrument of the Aerosol Robotic Network (AERONET), the Cimel CE-318 Sun photometer. The first part of the analysis contains a preliminary study whose results conclude on the need of a Sun movement correction for an accurate evaluation of the pointing error from both new measurements. Once this correction is applied, both measurements show equivalent results with differences under $0.01^{\circ}$ in the pointing error estimations. The second part of the analysis includes the incorporation of the cross procedure in the AERONET routine measurement protocol in order to monitor the pointing error in field instruments. The pointing error was evaluated using the data collected for more than a year, in 7 Sun photometers belonging to AERONET sites. The registered pointing error values were generally smaller than $0.1^{\circ}$, though in some instruments values up to $0.3^{\circ}$ have been observed. Moreover, the pointing error analysis shows that this measurement can be useful to detect mechanical problems in the robots or dirtiness in the 4-quadrant detector used to track the Sun. Specifically, these mechanical faults can be detected due to the stable behavior of the values over time and vs. the solar zenith
\end{abstract}

angle. Finally, the matrix procedure can be used to derive the value of the solid view angle of the instruments. The methodology has been implemented and applied for the characterization of 5 Sun photometers. To validate the method, a comparison with solid angles obtained from the vicarious calibration method was developed. The differences between both techniques are below $3 \%$.

\section{Introduction}

The AErosol RObotic NETwork (AERONET, Holben et al., 1998) program was started by the National Aeronautics and Space Administration (NASA) in the 1990s, in collaboration with PHOTONS (Laboratoire d'Optique Atmospherique - LOA, University of Lille), as a federation of networks with regional or national extent deployed on ground in the form of stations for monitoring atmospheric aerosols. AERONET aims at providing reliable monitoring of global aerosol optical and microphysical properties, to facilitate the characterization of the aerosol properties, the validation of satellite products related to the aerosol as well as the synergy with other instrumentation (lidar, surface radiation, in situ aerosol, etc.).

For these purposes, the network imposes standardization of instruments, measurements, calibration, processing and data distribution, which have allowed its great expansion and wide usage in the scientific community. The standard 
AERONET instrument is the CE-318 manufactured by Cimel Electronique. This is an automatic Sun and sky radiometer, equipped with 8 or 9 spectral channels covering the spectral range $340-1640 \mathrm{~nm}$. It performs both direct Sun measurements and sky radiance observations in the almucantar and principal plane configurations (Holben et al., 1998).

The AERONET inversion algorithm, described in Dubovik and King (2000) (also Dubovik et al., 2000, 2002, 2006), provides the aerosol information from two kinds of measurements: spectral data of direct Sun radiation extinction (i.e., aerosol optical depth) and angular distribution of sky radiance. The latter contains essential information for retrieving the aerosol phase function and optical aerosol properties. Using this information, important aerosol optical and microphysical parameters, such as the particle size distribution (Nakajima et al., 1983, 1996) and complex refractive index or single scattering albedo (Dubovik and King, 2000; Dubovik et al., 2006), are derived.

The work of Dubovik et al. (2000) describes an accuracy analysis of the AERONET inversion code considering different error sources. Among the different error sources, a possible azimuth angle error during the pointing process is also accounted for. Precisely, one of the most important results of the study is that an accurate azimuth angle pointing is critical for the characterization of desert dust aerosol. The zenith pointing accuracy, as analyzed by Torres (2012) is shown to be critical for the principal plane retrievals.

However, an evaluation of the pointing error in the Cimel CE-318 Sun photometers has not been done yet. The present work analyzes the first results of two new measurements (also called "scenarios" following the Cimel terminology), denominated "cross" and "matrix" and integrated in the CE318 , which have been developed for a characterization of the pointing error. As will be shown, these measurements will not be only useful to characterize the azimuth pointing error, but they will also be used to estimate the zenith pointing error whose perturbations in the inversion procedure are mentioned above. The continuous monitoring of this pointing accuracy can also be used to monitor instrument performance in the field.

Finally, the matrix measurement allows calculating the field of view (FOV) of the Sun photometer. This characteristic is of great importance in any Sun photometer, but the need for an accurate determination (beyond the manufacturer's specifications) arises from the fact that the field of view can be used to calibrate the radiance channels using the vicarious method (Li et al., 2008). Both field and laboratory measurements of the FOV can be used as a calibration check for quality assurance.

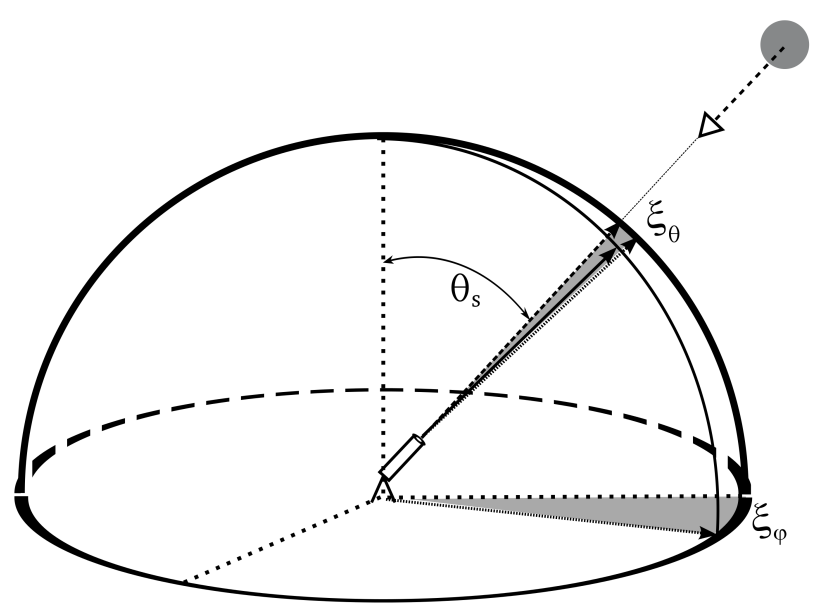

Fig. 1. Figure used to describe the pointing error. Dashed vector pointing towards the Sun represents the correct pointing, while solid line represents a biased pointing. Shading areas are the projection of this error in spherical coordinates: $\xi_{\varphi}$ and $\xi_{\theta}$.

\section{Theoretical basis}

\subsection{Pointing error}

\subsubsection{Definition}

Pointing error (see Fig. 1) is defined as the angle between the Sun position (correct pointing) and the erroneous pointing direction. As Sun photometers are moved by two motors, azimuth and zenith axes, the value of the pointing error, $\Theta_{\xi}$, is normally given in spherical coordinates:

$\Theta_{\xi}=\Theta_{\xi}\left(\xi_{\varphi}, \xi_{\theta}\right)$.

Unfortunately, the procedures conceived to calculate the pointing error generate $\xi_{\varphi}$ and $\xi_{\theta}$ but not the "total" pointing error $\Theta_{\xi}$. So, the relation between $\xi_{\varphi}, \xi_{\theta}$ and $\Theta_{\xi}$ should be obtained. Note, here, that if the pointing error is sufficiently small, it can be considered as an infinitesimal displacement (given in spherical coordinates) and therefore the relation in Eq. (1) could be defined as

$$
\begin{aligned}
\Theta_{\xi} & =\Theta_{\text {error }}\left(\xi_{\varphi}, \xi_{\theta}\right)=\xi_{\theta} \hat{\theta}+\sin \theta_{\mathrm{s}} \xi_{\varphi} \hat{\varphi} \\
\Theta_{\xi} & =\sqrt{\xi_{\theta}^{2}+\sin \theta_{\mathrm{s}}{ }^{2} \xi_{\varphi}^{2}} .
\end{aligned}
$$

To calculate the general relation of Eq. (1), the concept of scattering angle needs to be defined.

\subsubsection{Scattering angle}

The concept of scattering angle is very interesting in many fields of physics, playing a fundamental role in the field of atmospheric optics. In this context, the scattering angle is defined as the angle between the forward direction of the sunbeam and a straight line connecting the scattering point 


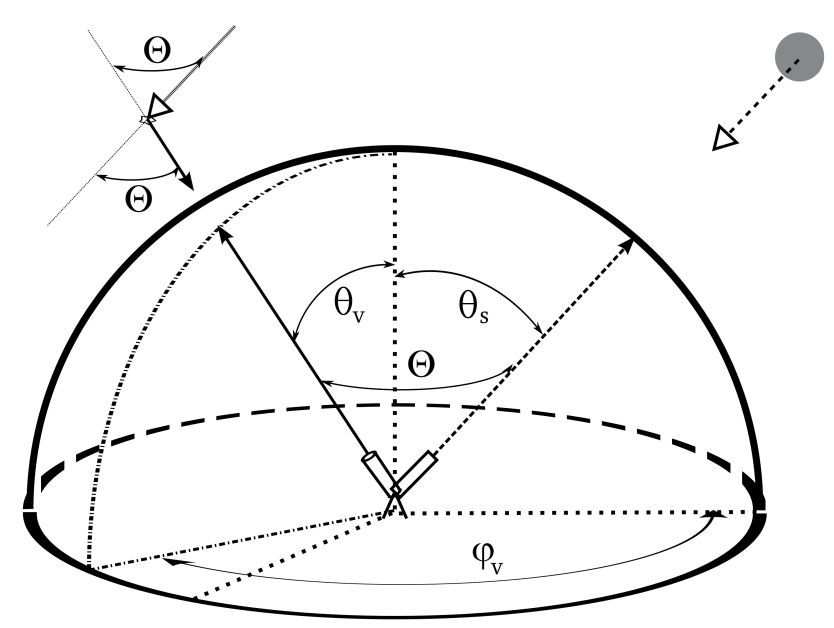

Fig. 2. Figure used to describe the scattering angle in terms of solar position and the observation angle.

observed by a detector. In our particular case, where the detector is a ground-based Sun photometer, the Sun can be considered to be in the infinite and the scattering angle is equivalent to the angle formed by the directions of the Sun and the observation from the detector; see Fig. 2.

Then, the relation between the scattering angle, the solar position and the observation angle can be written as in Vermeulen (1996):

$\cos (\Theta)=\cos \left(\theta_{\mathrm{S}}\right) \cos \left(\theta_{\mathrm{V}}\right)+\sin \left(\theta_{\mathrm{S}}\right) \sin \left(\theta_{\mathrm{V}}\right) \cos \left(\varphi_{\mathrm{V}}-\varphi_{\mathrm{S}}\right)$,

where $\Theta$ is the scattering angle, $\varphi_{\mathrm{v}}$ and $\theta_{\mathrm{v}}$ are the observation azimuth and zenith angle, and $\theta_{\mathrm{s}}$ the solar zenith angle. In the representation system, the solar azimuth angle $\left(\varphi_{\mathrm{s}}\right)$ can be taken as the azimuth origin and its value set to zero.

\subsubsection{Pointing errors described in terms of the scattering angle}

Revising both definitions, pointing error and scattering angle, it is easy to observe how the pointing error can be re-defined as the scattering angle of the erroneous pointing direction. If $\xi_{\varphi}$ and $\xi_{\theta}$ are the spherical coordinates of the pointing error, using Eq. (3), their relation with the scattering angle can be written as

$$
\begin{aligned}
\cos \left(\Theta_{\xi}\right)= & \cos \left(\theta_{\mathrm{s}}\right) \cos \left(\theta_{\mathrm{s}}+\xi_{\theta}\right) \\
& +\sin \left(\theta_{\mathrm{s}}\right) \sin \left(\theta_{\mathrm{s}}+\xi_{\theta}\right) \cos \left(\xi_{\varphi}\right),
\end{aligned}
$$

which expresses the exact relation of the total pointing error in terms of $\xi_{\varphi}$ and $\xi_{\theta}$. If we develop $\cos \left(\theta_{\mathrm{S}}+\xi_{\theta}\right)$ and $\sin \left(\theta_{\mathrm{s}}+\right.$ $\left.\xi_{\theta}\right)$, then

$$
\begin{aligned}
\cos \left(\Theta_{\xi}\right)= & \cos \left(\theta_{\mathrm{S}}\right)\left[\cos \left(\theta_{\mathrm{S}}\right) \cos \left(\xi_{\theta}\right)-\sin \left(\theta_{\mathrm{S}}\right) \sin \left(\xi_{\theta}\right)\right] \\
+\sin \left(\theta_{\mathrm{S}}\right) & \cos \left(\xi_{\varphi}\right)\left[\cos \left(\theta_{\mathrm{S}}\right) \sin \left(\xi_{\theta}\right)+\sin \left(\theta_{\mathrm{S}}\right) \cos \left(\xi_{\theta}\right)\right] \\
= & \cos \left(\theta_{\mathrm{S}}\right)^{2} \cos \left(\xi_{\theta}\right)-\sin \left(\theta_{\mathrm{S}}\right) \cos \left(\theta_{\mathrm{S}}\right) \sin \left(\xi_{\theta}\right) \\
& +\sin \left(\theta_{\mathrm{S}}\right) \cos \left(\theta_{\mathrm{S}}\right) \sin \left(\xi_{\theta}\right) \cos \left(\xi_{\varphi}\right) .
\end{aligned}
$$

If again we only consider small errors, $\sin \left(\xi_{\theta}\right)$ can be approximated, rejecting terms from the third derivative, as $\xi_{\theta}$, and $\cos \left(\xi_{\theta}\right)$ eliminating terms from the fourth derivative as $1-\frac{\xi_{\theta}^{2}}{2}$. The same is valid for $\xi_{\varphi}$, obtaining

$$
\begin{aligned}
\cos \left(\Theta_{\xi}\right)= & \cos ^{2}\left(\theta_{\mathrm{s}}\right)-\cos ^{2}\left(\theta_{\mathrm{s}}\right) \frac{\xi_{\theta}^{2}}{2}-\sin \left(\theta_{\mathrm{s}}\right) \cos \left(\theta_{\mathrm{s}}\right) \xi_{\theta} \\
& +\sin \left(\theta_{\mathrm{s}}\right) \cos \left(\theta_{\mathrm{s}}\right) \xi_{\theta} \cos \left(\xi_{\varphi}\right) \\
& +\sin ^{2}\left(\theta_{\mathrm{s}}\right)\left(1+\frac{\xi_{\theta}^{2} \xi_{\varphi}^{2}}{4}-\frac{\xi_{\theta}^{2}}{2}-\frac{\xi_{\varphi}^{2}}{2}\right)
\end{aligned}
$$

and then

$$
\begin{aligned}
\cos \left(\Theta_{\xi}\right)=1 & +\sin \left(\theta_{\mathrm{S}}\right) \cos \left(\theta_{\mathrm{S}}\right) \sin \left(\xi_{\theta}\right)\left(\cos \left(\xi_{\varphi}\right)-1\right) \\
& -\left(\cos ^{2}\left(\theta_{\mathrm{S}}\right) \frac{\xi_{\theta}^{2}}{2}+\sin ^{2}\left(\theta_{\mathrm{S}}\right) \frac{\xi_{\theta}^{2}}{2}\right) \\
& -\sin ^{2}\left(\theta_{\mathrm{S}}\right) \frac{\xi_{\varphi}^{2}}{2}+\sin ^{2}\left(\theta_{\mathrm{S}}\right) \frac{\xi_{\theta}^{2} \xi_{\varphi}^{2}}{4} \\
\cos \left(\Theta_{\xi}\right)=1 & -\frac{\xi_{\theta}^{2}}{2}-\sin ^{2}\left(\theta_{\mathrm{S}}\right) \frac{\xi_{\varphi}^{2}}{2} \\
& -\sin \left(\theta_{\mathrm{S}}\right) \cos \left(\theta_{\mathrm{S}}\right) \frac{\xi_{\theta} \xi_{\varphi}^{2}}{2}+\sin ^{2}\left(\theta_{\mathrm{S}}\right) \frac{\xi_{\theta}^{2} \xi_{\varphi}^{2}}{4}
\end{aligned}
$$

and at this point, if we consider again only those terms until the second order, the last two terms in Eq. (10) can be eliminated. On the other hand, if we also approximate $\cos \left(\Theta_{\xi}\right)$ as $1-\frac{\Theta_{\xi}^{2}}{2}$, then

$$
\begin{gathered}
1-\frac{\Theta_{\xi}^{2}}{2}=1-\frac{\xi_{\theta}^{2}}{2}-\sin ^{2}\left(\theta_{\mathrm{s}}\right) \frac{\xi_{\varphi}^{2}}{2} \\
\Longrightarrow \Theta_{\xi}^{2}=\xi_{\theta}^{2}+\sin \theta^{2} \xi_{\varphi}^{2},
\end{gathered}
$$

recovering the expression in Eq. (2).

Taking into account that the pointing errors will not be larger than $1^{\circ}$, all the approximations made (which rejected terms from the third order) are valid and, therefore, pointing errors can be separated into their azimuth and zenith components.

The first tests done in order to characterize the pointing error, presented in the next section, confirmed this result: the zenith component of the error, $\xi_{\theta}$, was constant and the azimuth one, $\xi_{\varphi}$, was also constant if it was multiplied by $\sin \theta_{\mathrm{s}}$. Therefore, the pointing error can be seen as a consistent magnitude, intrinsic to every photometer, which can be defined as the scattering angle between the sunbeam and the direction in which its detector is pointing.

In order to make the description easier, $\xi_{\theta}$ and $\xi_{\varphi}$, which are related to the two motor movements (zenith and azimuth), will be denoted from now on as zenith and azimuth error, respectively. On the other hand, total vertical and horizontal error will be denoted $\Theta_{\xi_{\theta}}=\xi_{\theta}$ and $\Theta_{\xi_{\varphi}}=\sin \theta_{\mathrm{s}} \xi_{\varphi}$, respectively, which are the components of the pointing error in spherical coordinates. Needless to say, zenith and vertical errors are coincident, and sometimes we will refer to them indistinctly. 


\subsection{Field of view of the Sun photometers}

\subsubsection{Definition}

Ideally, the solid angle in a radiance measurement is supposed to be infinitesimal. However, the solid angle is finite in the Sun photometers, and this fact could cause some disturbances in the radiance value.

According to the Cimel company, manufacturer of the Sun photometer Cimel-318, the value of the field of view ${ }^{1}$ in the current Sun photometers is $1.2^{\circ}$ while in the old versions it was $2.4^{\circ}$. The field of view is an important characteristic of the Sun photometers: in radiance measurements, a large field of view can yield undesired averaging of radiances at sky regions near the Sun in which the change of radiance with the scattering angle is steep. On the other hand, the direct solar irradiance measurements get biased by the amount of aureole radiation that is assumed to be direct solar radiation. An investigation on this particular topic in the frame of AERONET has been recently published (Sinyuk et al., 2012).

\subsubsection{Vicarious}

The so-called vicarious calibration method (Li et al., 2008) provides a radiance calibration given that an irradiance calibration and the solid view angle are known. The radiance $(L)$ can be defined as

$$
L=\frac{\mathrm{d} E}{\mathrm{~d} \Omega \cos (\theta)},
$$

where $E$ is the irradiance, $\Omega$ the solid angle and $\theta$ is the angle between the surface normal direction and the specified (incidence or view) direction.

For small solid angles at normal incidence, the radiance can be approximated as

$L=\frac{E}{\Omega}$.

The solid view angle of the instrument is just related to the geometry, provided that the irradiance (used for direct Sun observations) and the radiance (used for scattered sky radiance measurement) channels are measured with the same optical components, as is the case for the last generation of Cimel Sun/sky radiometers. The different electronic amplification used in each case must be taken into account. All the necessary information to derive the solid angle is indicated by Li et al. (2008, see Eq. 9).

In the cited work by $\mathrm{Li}$ et al. (2008), the authors derive the solid view angle from a set of irradiance and radiance calibrations, the latter made using an integrating sphere with known radiance output. In this work, we will apply the vicarious method to derive the field of view. This estimation

\footnotetext{
${ }^{1}$ Note that the relation between the solid angle [sr] and field of view [radian] can be expressed as: $\Omega=2 \pi(1-\cos \theta)$ being $\theta$ the field of view divided by two.
}

is based on the AERONET direct Sun and radiance calibrations; therefore it is independent of the geometrical measurements (in the laboratory or using the Sun as a source) of the field of view that are described in the next section. A comparison of results from 3 instruments will be presented to carry out a first consistency check between methods.

\section{New procedures: matrix and cross}

Two new procedures, matrix and cross, have been developed with the aim of evaluating the pointing quality of the Sun photometers. The description of both of them, as well as the different implementations accomplished in order to make them operative, are presented in this section.

Before describing the new procedures, it is necessary to briefly explain how the Cimel Sun photometer points at the Sun during its automated operation. The photometer robot has origin positions in both the zenith and azimuth motors. These are found with the so-called PARK procedure, or scenario. Once the parking position is achieved, the instrument tries to find the Sun following an astronomical calculation (GOSUN scenario) based on site coordinates and time. Due to incorrect leveling or robot orientation this position is usually not perfect. Finally a 4-quadrant detector is used (TRACK scenario) to find the exact solar position. The 4quadrant must be previously adjusted (initially by the manufacturer) so that the instrument finds the position of maximum signal on the detector while pointing at the Sun or a solar simulator, which is assumed to be the optical axis of the system. The adjustment can be lost due to several reasons: incorrect manipulation for example during transport, dirtiness on the 4-quadrant window, deficient alignment during maintenance, etc.

Other causes of a bad pointing can be also related to the mechanical performance of the tracking robot, which can have some slack in the motors or loose screws, or even arise from incorrect instrument setup, for instance if some cable does not allow free instrument movement. However, these last cases result in not finding the Sun at all within the field of view and are therefore easy to detect.

A small misalignment of the 4-quadrant detector may however remain unnoticed as long as the solar disk is entirely captured within the field of view in the direct Sun measurements (the tolerance is about $0.35^{\circ}$ in the Cimel Sun photometers). Such a slight deviation of tenths of a degree in the 4-quadrant adjustment will not affect the optical depths but may have significant influence on the sky radiances and therefore on the inversion-derived aerosol properties (Torres, 2012), as commented in the introduction. 

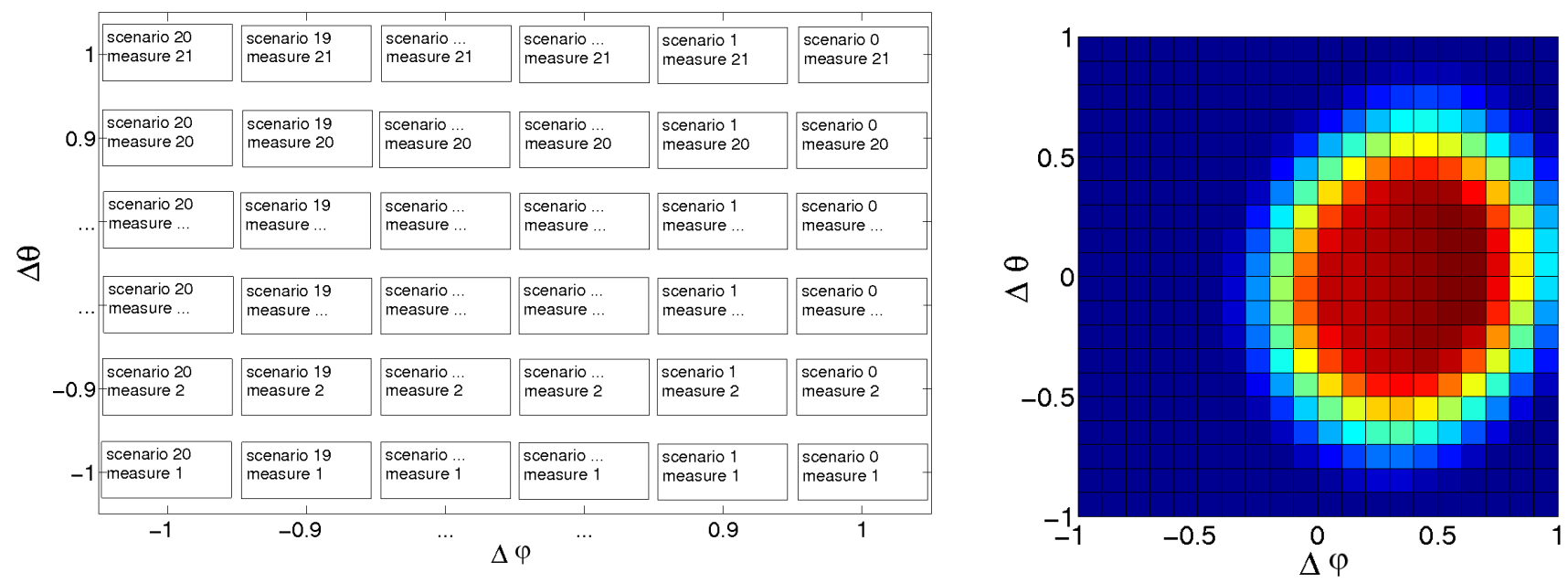

Fig. 3. Explanation of the matrix procedure in the subfigure on the left. On the right, a measurement taken at the Lille site on 22 September 2010 at 12:47:07 LT.

\subsection{Matrix measurement}

\subsubsection{Description}

The matrix measurement starts with go-sun and track procedures (pointing at the Sun), and afterwards the Cimel moves towards the right $\Delta \varphi=1^{\circ}$ and down $\Delta \theta=-1^{\circ}\left({ }^{1}\right)$. From this point it starts scanning the area around the Sun, going from down to up and right to left as plotted in Fig. 3 (on the left). As we can see in the figure, each data point represents a $0.1^{\circ}$ movement to the left from $\Delta \varphi=1^{\circ}$ to $\Delta \varphi=-1^{\circ}$, which results in 21 measurements. In each of these measurements the Cimel covers all the zenith angles from $\Delta \theta=-1^{\circ}$ to $\Delta \theta=1^{\circ}$ in $0.1^{\circ}$ steps, while keeping the azimuth angle fix, and records a total of 21 measurements. An example of a matrix measurement is given in Fig. 3 (on the right) taken at the Lille site on 22 September 2010 at 12:47:07 LT.

Time is recorded for each measurements, right-left movement. That sequence lasts around $10 \mathrm{~s}$; therefore every piece of data is obtained more or less every half a second. The total time used for the whole matrix measurement is $3.5 \mathrm{~min}$.

\subsubsection{Sun correction in matrix procedure}

The image produced by the matrix (Fig. 3 on the right) seems to be wrong at first glance. The cause of this strange result is the Sun movement during the matrix measurement. In order to illustrate how the Sun movement affects our measurements, we show a brief study of how fast the Sun moves in angular terms at middle latitudes. For this test, we used the algorithm presented by Reda and Andreas (2004), which

\footnotetext{
${ }^{1}$ Hereafter the azimuth displacement of the Sun photometer motor will be called $\Delta \varphi$, the zenith one being represented as $\Delta \theta$.
}
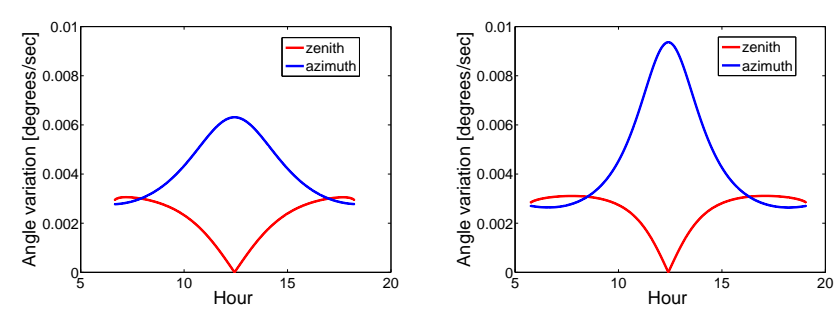

Fig. 4. Azimuth and zenith absolute Sun variations per second at the Valladolid site during the winter on the left, and during the summer on the right.

will be later used to discount the solar movement in the whole pointing error study. Using the mentioned algorithm, in Fig. 4, the zenith and azimuth absolute Sun variation per second at the Valladolid site (middle-latitude station) are represented, for the winter, in the subfigure on the left, and for the summer in the subfigure on the right.

The zenith variation never gets higher than $0.003^{\circ} \mathrm{s}^{-1}$, reaching this value at sunrise and at sunset, and its minimum at noon being $0^{\circ} \mathrm{s}^{-1}$. Looking at the figures, it does not show a seasonal variability. On the other hand, the azimuth variation is much higher and season-dependent: the variation reaches its maximum of $0.01^{\circ} \mathrm{s}^{-1}$ at noon in the summer. Its minimum of $0.003^{\circ} \mathrm{s}^{-1}$ takes place at dawn and at sunset (same value as the maximum of solar variation). With all these data, we can estimate that the bias introduced during the matrix measurement at a middle-latitude station is between $0^{\circ}$ and $0.6^{\circ}$ in the zenith and between $0^{\circ}$ and $2^{\circ}$ in the azimuth.

Once the Sun movement correction is applied to all the matrix data, and the matrix is re-sized, the same matrix as in 

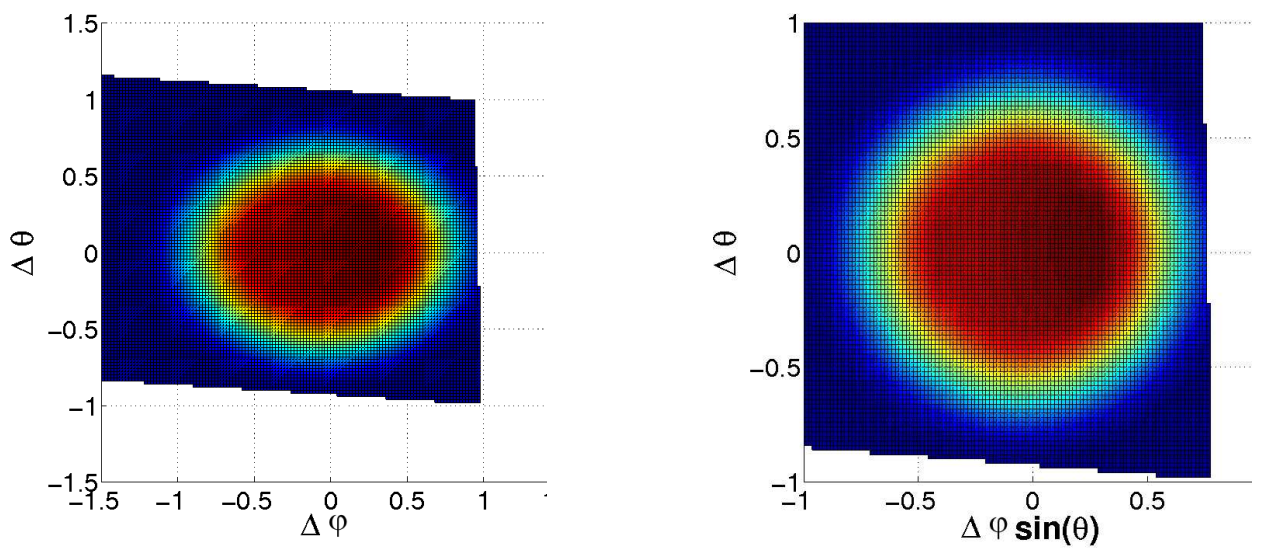

Fig. 5. Subfigure on the left shows a matrix measurement taken at the Lille site on 22 September 2010 at 12:47:07, corrected for the Sun displacement. Subfigure on the right displays the same measurement but with the azimuth displacement multiplied by $\sin \left(\theta_{\mathrm{S}}\right)$.

Fig. 3 is plotted in Fig. 5, on the left; note that in the figure on the right, $\Delta \varphi \sin \left(\theta_{\mathrm{s}}\right)$ is put instead of $\Delta \varphi$. The fact that in the first plot an ellipse appears while the second one shows a sphere confirms what we have already settled: even though the Sun photometer motor does the steps by $\Delta \varphi$, the horizontal Sun photometer pointing error should be evaluated in terms of $\Delta \varphi \sin \left(\theta_{\mathrm{s}}\right)$.

\subsection{Cross measurement}

\subsubsection{Description}

The Sun cross measurement starts tracking the Sun and then it moves downwards, $\Delta \theta=-4^{\circ}$. From this point, it moves up recording data for every step of $0.2^{\circ}$ (measurement 0 ). Once it gets to $\Delta \theta=4^{\circ}$ it repeats the movements but backwards (measurement 1). Afterwards, it points to the Sun again and moves right, $\Delta \varphi=4^{\circ}$. From there, it moves left recording data every $0.2^{\circ}$, as well, until $\Delta \varphi=4^{\circ}$ (measurement 2), and then it repeats the movement to the right until $\Delta \varphi=4^{\circ}$ again (measurement 3 ). The data obtained between $-2^{\circ}$ and $2^{\circ}$ in both axes are measured with low gain (Sun channel 1) like in the matrix measurement, and the rest of the data are recorded with a higher gain (aureole) channel. Nevertheless, the relevant part of the measurement is the first set of data.

\subsubsection{Sun correction in cross procedure}

Cross measurements need a correction due to the solar displacement too. Checking the timing recorded in the data files, from the beginning of the two track procedures (considering tracking time as the time recorded in the 0 and 2 measurements) until the end of measurements 1 and 3, the Sun photometer uses approximately $40 \mathrm{~s}$. The correction is especially critical for azimuth angles during the summer season, when a bias of $0.4^{\circ}$ would appear otherwise. The cross measurement
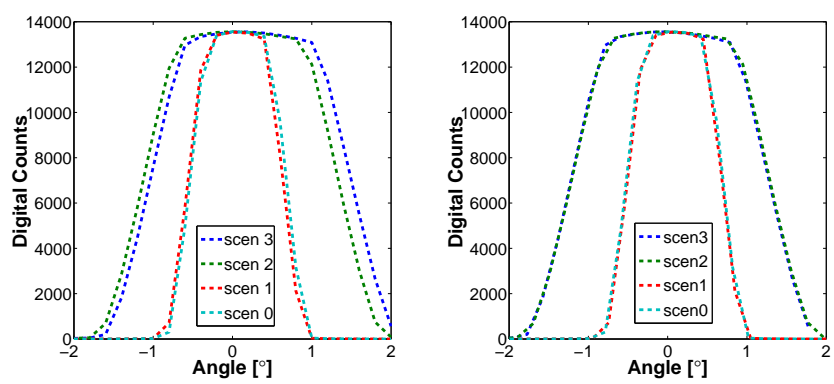

Fig. 6. On the left, cross measurements taken at the Valladolid site on 5 August 2010 at 13:41. The subfigure on the right shows the same measurement after applying a Sun movement correction on the data.

done at the Valladolid site on 5 August 2010 at 13:41 is shown in Fig. 6 with and without the Sun movement correction. In the example, the necessity of this correction can be seen, especially for measurement 3 (green line), which is the second measurement of the azimuth cross, as previously indicated.

\section{Pointing error estimations}

\subsection{Methodology}

After describing the procedures and the Sun movement correction, we will describe the methodology used to obtain the pointing bias with the matrix and the cross measurements. The analysis of the matrix measurements consists of obtaining the contour maps for levels between $20 \%$ and $80 \%$ of the maximum value (with steps of $5 \%$ ). Every line level describes an ellipse, as shown in the example in Fig. 7. 

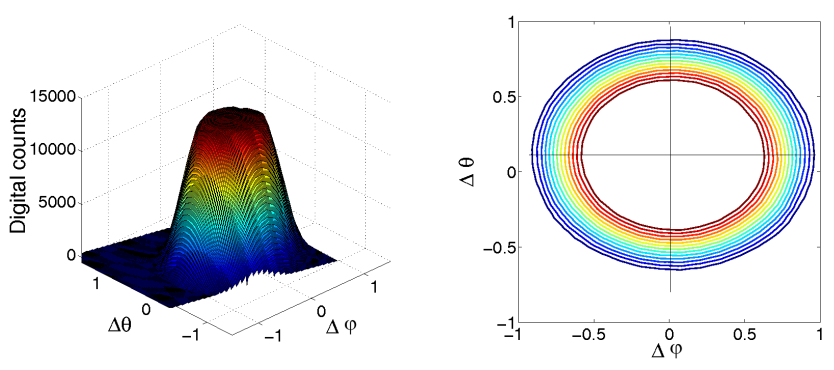

Fig. 7. Figure on the left, matrix measurement done at the Valladolid site on 5 August 2010 at 13:41 with a SZA of 54.77 , on the right its contour map for levels from $20 \%$ to $80 \%$ of its maximum value (every $5 \%$ ).

The value of the pointing error is then estimated by calculating all the centers and averaging them. A similar procedure is followed for the cross measurements. Using the data from measurements 0 and 1 (related to $\Delta \theta$ ) and measurements 2 and 3 (related to $\Delta \varphi$ ), the data is interpolated at different heights of its maximum value, in this case from $20 \%$ to $80 \%$ with steps of $10 \%$. It is important to emphasize again that the azimuth pointing estimation should be done as $\Delta \varphi \sin \left(\theta_{\mathrm{s}}\right)$, and consequently after the calculation of the centers (done in terms of $\Delta \varphi$ resulting in ellipses instead of circles in the matrix analysis), every single point is multiplied by $\sin \left(\theta_{\mathrm{s}}\right)$ to obtain the pointing error estimation.

\subsection{Preliminary results}

The first tests with the matrix and cross measurements were done in Valladolid during summer 2010 with photometer \#353, and in Lille during the early autumn 2010 with photometers \#042 and \#047. We also did some tests with photometers \#420 and \#143 in Valladolid during the autumn. Table 1 includes the dates and the description of all the data collected. Therefore, for these first tests, data were collected using 5 different Sun photometers.

The measurements from \#047 are split because two different robots were used during the measurement; when it was installed on the first robot, it showed some disagreements which are discussed separately. Once the photometer was set on the second robot, the disagreements disappeared.

The photometer number \#420 was studied in 4 periods because we deliberately misaligned its tracking system: numbers (2) and (3) correspond to those measurements with the biased track system, while numbers (1) and (4) represent the tests when the photometer came to the calibration center and before it was sent back to its field site, once the tracking system was re-adjusted.

Tables 2 and 3 contain the average and the standard deviation of the pointing error for all the data except for that of photometer \#047(1), which due to its aforementioned problems is analyzed apart. We have not included the tests with $\# 420$ (2) and \#420(3) either, since their tracking system was deliberately misaligned, and they will be also studied later. Table 2 shows the results obtained for the horizontal pointing error (azimuth pointing error multiplied by $\sin \left(\theta_{\mathrm{S}}\right)$ ) and Table 3 for vertical pointing error (or zenith pointing error). The same scheme is used for both tables: the column on the left presents the results obtained by the matrix, the second column the result obtained by the cross, while the third and four columns present the results for every cross branch individually.

The two procedures provide practically the same pointing errors with absolute differences under $0.01^{\circ}$ between them. This is a very important result as the measurements are independent and the methodology followed to calculate the pointing error was done separately. Another important result is that the Sun photometers point toward the Sun with an error under $0.1^{\circ}$ except for photometer \#143, whose tracking system seems to be biased $0.2^{\circ}$ in both axes.

Using the results of this photometer (with the highest error), the estimated pointing error of every single piece of data is plotted in Fig. 8 vs. date, on the left, and vs. the solar zenith angle (SZA) on the right in order to check whether there is any pointing error dependence on those parameters. The results do not show any dependence either on the date or on the solar zenith angle.

However, the data range for both components of the pointing error is around $0.07-0.08$. The result is not surprising as in Tables 2 and 3 the standard deviation was $0.020-0.025$ for all the photometers. This high dispersion could be explained by the mechanical characteristic of the Cimel-318 robot which has a minimum step of $0.05^{\circ}$ in azimuth and zenith. Note that the dispersion is also given in horizontal and vertical terms. As the solar zenith angles used for the measurements are very high there is almost no difference between the two components. However, as the dispersion is a function of the azimuth and zenith components of the motor, it should be understood in these terms; therefore, we would expect the horizontal dispersion to get reduced for short solar zenith angles, which is already noticeable in Fig. 8 (blue points in the figure on the right) when $\mathrm{SZA}=50^{\circ}$.

\subsubsection{Detection of robot problems: \#047}

Looking at the values of photometer \#047(1) in Table 4, there is no agreement between the matrix and cross results and not even between the two branches of the cross measure (measurement (2) and measurement (3) for $\Theta_{\xi_{\varphi}}$ and measurement (0) and measurement (1) for $\Theta_{\xi_{\theta}}$ ). Moreover, standard deviations of both sets are very high, reaching values of $0.1^{\circ}$, as is also visible in Table 4 and in Fig. 9, which illustrates the pointing error for the photometer \#047(1) as a function of the date. Nevertheless, as soon as the photometer was set on a different robot the error was corrected (re-named photometer $\# 047$ (2) as commented in the previous section and included in Tables 2 and 3), resulting in identifying problems in the robot as the cause of the dispersions. 
Table 1. Summary of the cross and matrix measurements done in the preliminary result tests.

\begin{tabular}{lcccc}
\hline Station & Photometer & Starting date & Ending date & Valid measur. \\
\hline Valladolid & $\# 353$ & $04 / 08 / 2010$ & $06 / 08 / 2010$ & 19 \\
Lille & $\# 042$ & $22 / 09 / 2010$ & $24 / 09 / 2010$ & 38 \\
Valladolid & $\# 143$ & $08 / 10 / 2010$ & $17 / 10 / 2010$ & 110 \\
Lille & $\# 047(1)$ & $09 / 10 / 2010$ & $12 / 10 / 2010$ & 107 \\
Valladolid & $\# 420(1)$ & $18 / 10 / 2010$ & $18 / 10 / 2010$ & 34 \\
Lille & $\# 047(2)$ & $21 / 10 / 2010$ & $28 / 10 / 2010$ & 65 \\
Valladolid & $\# 420(2)$ & $26 / 10 / 2010$ & $01 / 11 / 2010$ & 65 \\
Valladolid & $\# 420(3)$ & $02 / 11 / 2010$ & $08 / 11 / 2010$ & 91 \\
Valladolid & $\# 420(4)$ & $09 / 11 / 2010$ & $11 / 11 / 2010$ & 27 \\
\hline
\end{tabular}

Table 2. Summary of the horizontal pointing error $\left(\Theta_{\xi_{\varphi}}=\xi_{\varphi} \sin \left(\theta_{\mathrm{S}}\right)\right.$, given in degrees) for several Sun photometers in the preliminary result tests.

\begin{tabular}{|c|c|c|c|c|c|c|c|c|}
\hline \multirow[t]{2}{*}{ Photo. } & \multicolumn{2}{|c|}{ MATRIX } & \multicolumn{2}{|c|}{ CROSS } & \multicolumn{2}{|c|}{ Cross-Scen (2) } & \multicolumn{2}{|c|}{ Cross-Scen (3) } \\
\hline & mean & std & mean & std & mean & std & mean & std \\
\hline \#353 & 0.041 & 0.021 & 0.050 & 0.024 & 0.044 & 0.023 & 0.057 & 0.023 \\
\hline \#042 & -0.058 & 0.018 & -0.062 & 0.016 & -0.065 & 0.016 & -0.059 & 0.016 \\
\hline \#143 & 0.163 & 0.019 & 0.156 & 0.020 & 0.148 & 0.029 & 0.163 & 0.021 \\
\hline \#420(1) & 0.115 & 0.017 & 0.118 & 0.019 & 0.115 & 0.019 & 0.120 & 0.020 \\
\hline$\# 047(2)$ & -0.110 & 0.027 & -0.108 & 0.024 & -0.109 & 0.023 & -0.107 & 0.025 \\
\hline \#420(4) & -0.082 & 0.015 & -0.069 & 0.017 & -0.093 & 0.130 & -0.067 & 0.019 \\
\hline
\end{tabular}

\subsubsection{Misalignment tests}

Finally, the study of the instrument in which we deliberately misaligned its tracking system, number \#420, is shown in Table 1: \#420(2) and \#420(3). The center estimations for both periods are represented in Fig. 10. Before the Sun photometer was installed, on the morning of 27 October 2010, the tracking system was misaligned (\#420(2)). In order to investigate an even higher pointing error, it was misaligned again during the afternoon of that day. This change is noticeable in Fig. 10 (on the left) where the pointing error values are different in the morning and in the afternoon on 27 October 2010. To conclude, in the right part of Fig. 10, the evolution of the pointing error on the following days is shown. There is a total agreement for matrix and cross center estimations in this case, as well. Therefore, even when the tracking system is highly biased (values up to $0.5^{\circ}$ ) the method is still valid.

\subsubsection{Pointing error monitoring in the field}

The previous analysis suggested that matrix and cross measurements are both valid methods to estimate the pointing errors as well as good indicators of different issues, such as robot problems or dirtiness in the quadrant detector (Torres, 2011). After this, the cross measurement was proposed (within AERONET annual calibration workshop) to be integrated as a part of the AERONET standard measurement protocol, with a little modification: in order to be more precise the cross spans from $-2^{\circ}$ to $2^{\circ}$, with $0.1^{\circ}$ steps. Matrix measurement was discarded for field operation because a lot of memory is needed to record the data.

In order to integrate the cross measurement in the measurement protocol, the Cimel company designed a new Eeprom $(5.20 \mathrm{~h})$ that adds 2 cross measurements per day to the usual measurement protocol. These are all CE-318NE ("extended" model with $1640 \mathrm{~nm}$ channel). Note that the pointing measurements in previous sections with the matrix and cross measurements were based on the $1020 \mathrm{~nm}$ Sun channel exclusively. Cimel Sun photometers have 2 optical channels (with 2 collimator tubes). Depending on the Cimel models, the sky measurements are taken with the second optical channel (standard model) or with the same optical channel (extended model), given that extended models use the second channel for near infrared measurements at $1640 \mathrm{~nm}$ wavelength. The 4-quadrant detector is unique though; therefore the parallelism between tubes may play a role. The choice of an extended Cimel model for these measurements allows evaluating the pointing in both physical channels and provides an estimation of the parallelism between the two optical axes. This gives an estimation of the pointing error of the sky measurements in standard Cimels.

Seven AERONET Sun photometers calibrated by LOA or GOA (Group of Atmospheric Optics, Valladolid University) in Lille or Valladolid, respectively, have been operated with these routine cross measurements (twice a day) for more than a year. As explained above, these are all CE-318NE 
Table 3. Summary of the vertical pointing error $\left(\Theta_{\xi_{\theta}}=\xi_{\theta}\right)$ of several Sun photometers in the preliminary result tests.

\begin{tabular}{|c|c|c|c|c|c|c|c|c|}
\hline \multirow[t]{2}{*}{ Photo. } & \multicolumn{2}{|c|}{ MATRIX } & \multicolumn{2}{|c|}{ CROSS } & \multicolumn{2}{|c|}{ Cross-Scen $(0)$} & \multicolumn{2}{|c|}{ Cross-Scen (1) } \\
\hline & mean & std & mean & std & mean & std & mean & std \\
\hline \#353 & 0.079 & 0.020 & 0.079 & 0.015 & 0.084 & 0.014 & 0.073 & 0.016 \\
\hline \#042 & 0.021 & 0.018 & 0.020 & 0.018 & 0.022 & 0.018 & 0.019 & 0.019 \\
\hline \#143 & -0.199 & 0.021 & -0.208 & 0.022 & -0.210 & 0.024 & -0.207 & 0.029 \\
\hline \#420(1) & 0.025 & 0.019 & 0.019 & 0.015 & 0.023 & 0.015 & 0.016 & 0.015 \\
\hline$\# 047(2)$ & -0.046 & 0.020 & -0.049 & 0.025 & -0.034 & 0.023 & -0.064 & 0.026 \\
\hline \#420(4) & 0.052 & 0.019 & 0.053 & 0.023 & 0.065 & 0.050 & 0.049 & 0.023 \\
\hline
\end{tabular}
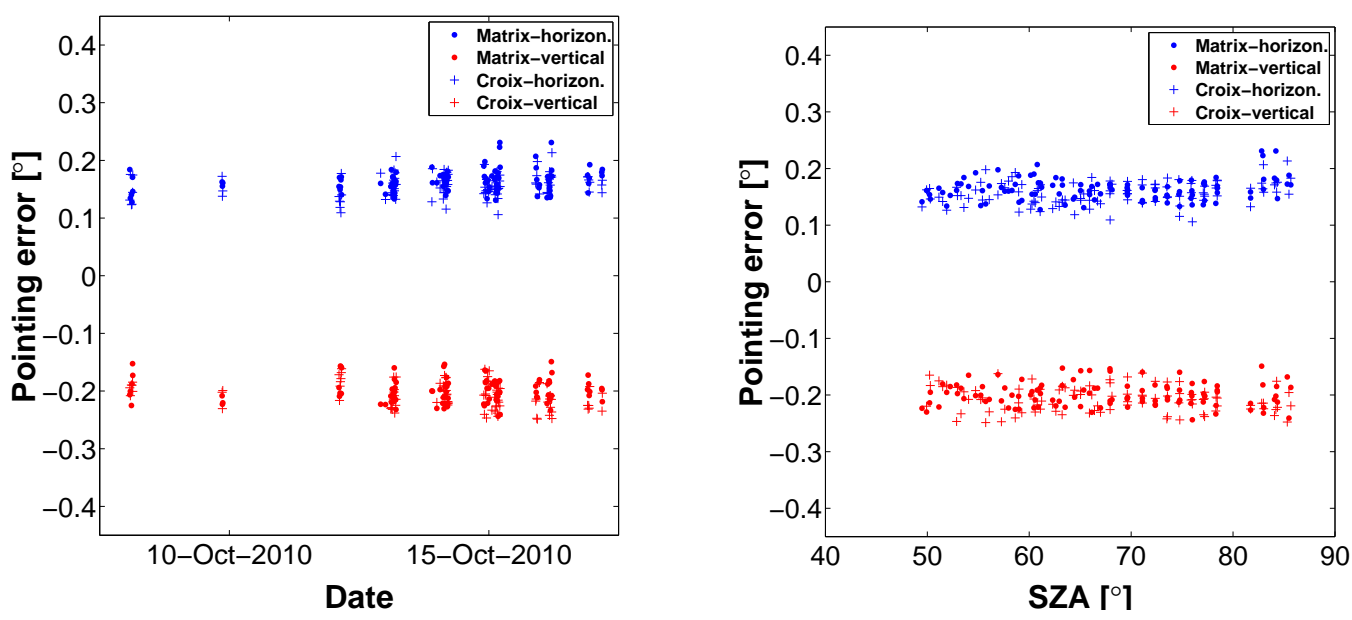

Fig. 8. Estimated center for matrix and cross measurements variation with the date (left) and with the SZA (right) for photometer \#143.

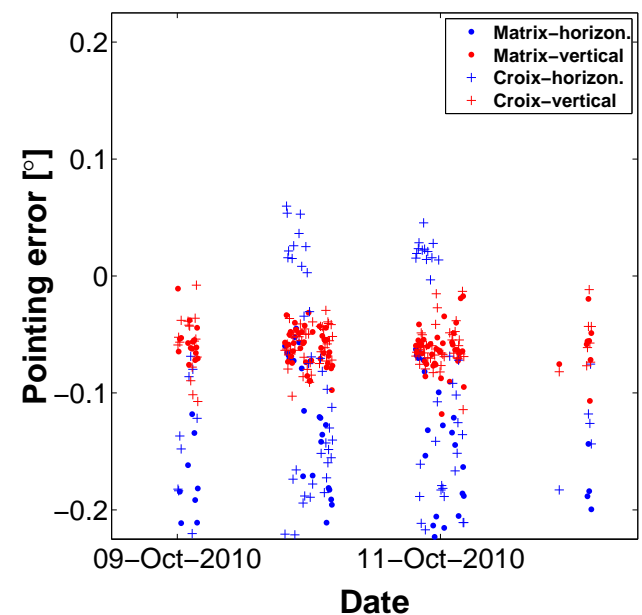

Fig. 9. Estimated center for matrix and cross measurements for photometer \#047.

("extended" model with $1640 \mathrm{~nm}$ channel). As an example, Fig. 11 shows the pointing error derived from crosses during 2012 for Sun photometer \#627 in both physical channels, corresponding to the UV visible and infrared channels, respectively. The two channels have different pointing axes and both of them stay within the prescribed specifications.

The pointing error observations derived from cross measurements have been shown to be very stable over time; therefore they would allow (a) correction of the pointing in the sky radiances, which could improve the inversion-derived products, and (b) detection of mechanical problems, as was already indicated in Sect. 4.2.1. In Fig. 12, the time series of pointing error in the zenith and zenith directions is shown for instrument \#383. In the analyzed period the instrument was deployed at several sites (Autilla, Valladolid and Izaña). A mechanical problem of the first robot used at Autilla is clearly highlighted by the azimuth pointing error. The problem is solved after the change of mounting robot. The installation in Valladolid shows very low and stable pointing errors. The last period in Izaña seems to present some deficiency in the azimuth direction, very likely due to some robot problem again.

Finally, Table 5 shows basic statistics on pointing errors for the photometers in the field for the 7 Sun photometer under analysis. Cross measurements are done just after a Sun direct measurement, and this fact has allowed to assure the selection of those measurements not affected by clouds, applying the same cloud screening procedure as the 
Table 4. Summary of the horizontal pointing error $\left(\Theta_{\xi_{\varphi}}=\xi_{\varphi} \sin \left(\theta_{\mathrm{S}}\right)\right)$ and vertical pointing error $\left(\Theta_{\xi_{\theta}}=\xi_{\theta}\right)$, both given in degrees, of photometer \#047.

\begin{tabular}{|c|c|c|c|c|c|c|c|c|c|}
\hline \multirow[t]{2}{*}{ Photo. } & \multirow[t]{2}{*}{ Error } & \multicolumn{2}{|c|}{ MATRIX } & \multicolumn{2}{|c|}{ CROSS } & \multicolumn{2}{|c|}{ Cross-Scen (2) } & \multicolumn{2}{|c|}{ Cross-Scen (3) } \\
\hline & & mean & std & mean & std & mean & std & mean & std \\
\hline \multirow[t]{3}{*}{$\# 047(1)$} & $\Theta_{\xi_{\varphi}}$ & -0.220 & 0.101 & -0.125 & 0.102 & -0.233 & 0.112 & -0.020 & 0.095 \\
\hline & & & & & & \multicolumn{2}{|c|}{ Cross-Scen $(0)$} & \multicolumn{2}{|c|}{ Cross-Scen (1) } \\
\hline & & mean & std & mean & std & mean & std & mean & std \\
\hline$\# 047(1)$ & $\Theta_{\xi_{\theta}}$ & -0.061 & 0.017 & -0.059 & 0.019 & -0.055 & 0.019 & -0.064 & 0.020 \\
\hline
\end{tabular}
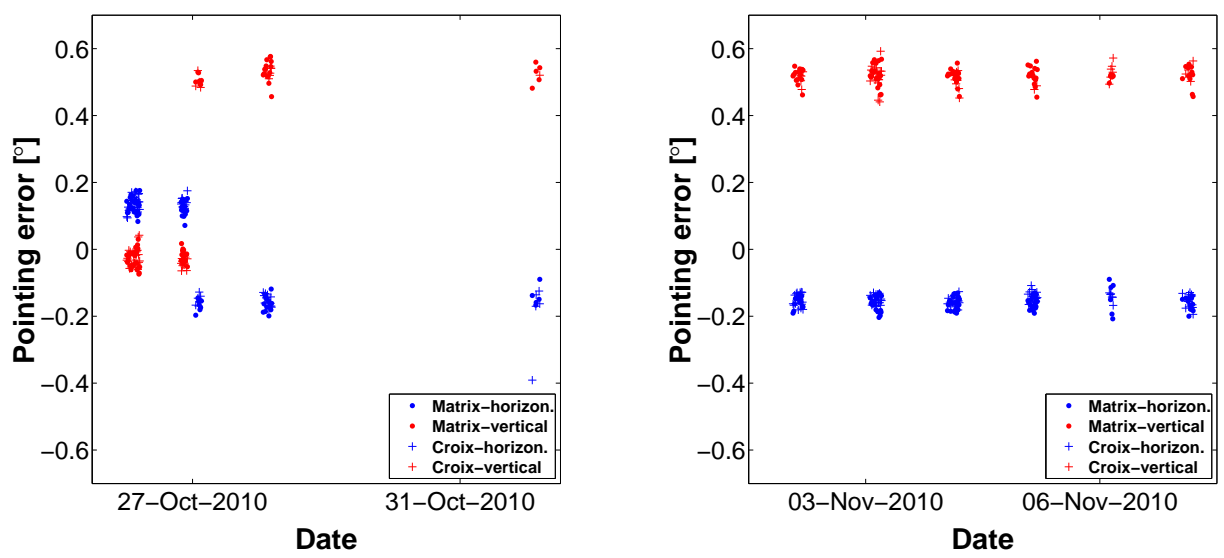

Fig. 10. Estimated center for matrix and cross measurements during the tests with the tracking system of Sun photometer \#420.

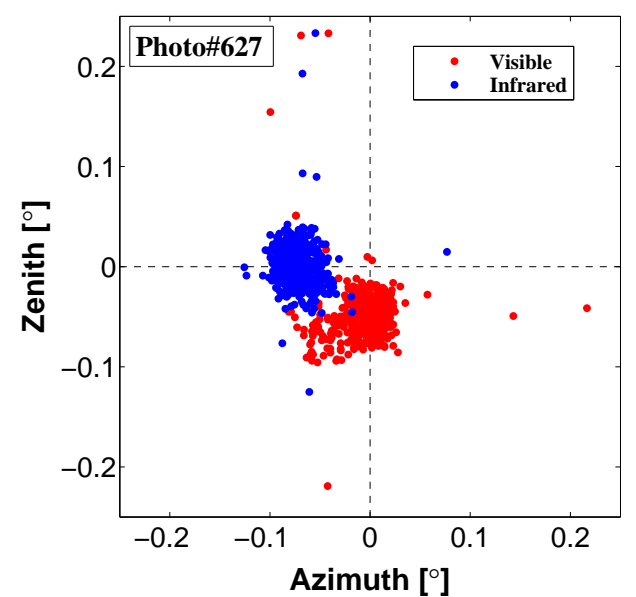

Fig. 11. Zenith and azimuth pointing error derived from cross measurements for Sun photometer \#627 during 2012.

one existing in AERONET for aerosol optical depth measurements (fully described in Smirnov et al., 2000). To eliminate from the analysis the different errors reported during the cross measurement (e.g., robot issues in Sun photometer \#383; Fig. 12) automatically, the maximum differences allowed between the branches, left-right and up-down, during the pointing error calculation has been $0.02^{\circ}$ (note that the final value of the pointing error is the average of these branches).

The results are indicative of good pointing adjustment overall, with average pointing error below $0.1^{\circ}$ in both directions for all the photometers except \#421. For this photometer the average of the zenith pointing error is $0.24^{\circ}$ and $0.14^{\circ}$, for the visible and infrared channel, respectively, though values up to $0.3^{\circ}$ have been registered in specific measurements. Note that most of the instruments were master instruments operating in calibration platforms (Izaña, Valladolid and $\mathrm{Au}-$ tilla); therefore it could be expected that different results are obtained from normal field instruments. On the other hand, the differences between the visible and infrared channel (i.e., the two collimators) are typically under $0.05^{\circ}$, except for the mentioned case of zenith pointing error in photometer \#421, indicating the good parallelism of collimators for Sun and sky measurements. 


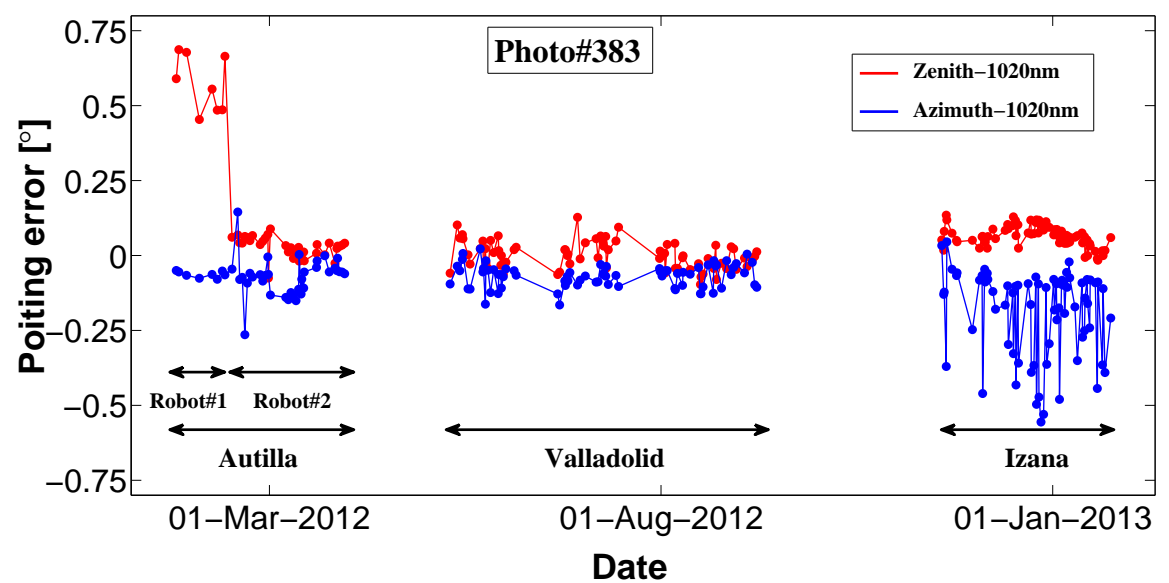

Fig. 12. Time series of zenith and azimuth pointing error derived from cross measurements for Sun photometer \#383 during 2012.

Table 5. Pointing error statistics for the 7 analyzed photometers in the azimuth $(\mathrm{Az})$ and zenith $(\mathrm{Zn})$ directions. The data are provided for the two physical channels, visible and infrared, in order to check also the parallelism between them.

\begin{tabular}{cccccr}
\hline Photo. & $\mathrm{Az}_{\text {vis }}$ & $\mathrm{Zn}_{\text {vis }}$ & $\mathrm{Az}_{\text {ir }}$ & $\mathrm{Zn}_{\text {ir }}$ & Valid measur. \\
\hline$\# 383$ & -0.06 & 0.03 & -0.06 & 0.04 & 92 \\
$\# 390$ & -0.06 & -0.06 & -0.08 & -0.06 & 43 \\
$\# 419$ & -0.05 & -0.08 & -0.08 & -0.09 & 150 \\
$\# 421$ & -0.02 & 0.24 & -0.04 & 0.14 & 411 \\
$\# 513$ & -0.04 & 0.01 & -0.02 & 0.05 & 51 \\
$\# 544$ & -0.07 & 0.10 & -0.10 & 0.02 & 161 \\
$\# 627$ & -0.01 & -0.05 & -0.07 & 0.00 & 287 \\
Total & -0.04 & 0.07 & -0.06 & 0.04 & 1196 \\
\hline
\end{tabular}

\section{Field of view calculations}

\subsection{Matrix measurements in field photometers}

Nakajima et al. (1996) propose a method to estimate the field of view from similar measurements to the matrix procedure. In this article, the field of view of the solar radiometer PREDE (standard instrument of the Skynet network) is calculated from a set of measurements similar to the matrix procedure. Basically, the field of view is obtained as follows:

F.O.V. $=\iint_{\Delta A} \frac{E(x, y)}{E(0,0)} \mathrm{d} x \mathrm{~d} y$

where $x$ and $y$ (in radians) are the polar coordinates that determine the position of the optical axis with respect to the position of the Sun. $E(x, y)$ is the irradiance measurement at any point and $E(0,0)$ is the irradiance at the center of the Sun.

In order to use Eq. (14) it is necessary to evaluate the measurement $E(0,0)$ and, therefore, to know previously the
Table 6. Values of the field of view (in degrees) calculated during the preliminary tests using the Sun as a light source.

\begin{tabular}{ccc}
\hline Photo. & F.O.V & std \\
\hline$\# 353$ & 1.30 & 0.02 \\
$\# 042$ & 1.27 & 0.03 \\
$\# 143$ & 1.14 & 0.02 \\
$\# 047(2)$ & 1.30 & 0.02 \\
$\# 420(1)$ & 1.32 & 0.02 \\
$\# 420(2)$ & 1.32 & 0.02 \\
$\# 420(3)$ & 1.32 & 0.03 \\
$\# 420(4)$ & 1.32 & 0.03 \\
\hline
\end{tabular}

pointing error. If $x_{\mathrm{c}}$ and $y_{\mathrm{c}}$ are the estimated pointing errors (horizontal and vertical, respectively), then Eq. (14) can be expressed as

F.O.V. $=\sum_{i, j} \frac{E\left(x_{i}, x_{j}\right) \Delta S(i, j)}{E\left(x_{\mathrm{c}}, y_{\mathrm{c}}\right)}$,

where $i$ represents the variation in the horizontal (azimuth increment multiplied by $\sin \theta_{\mathrm{s}}$ ) axes and $j$ in the zenith one.

Using the photometers described in Table 1, in Table 6 calculated values for the field of view are represented. Photometer \#047 in its first part is not represented due to its robot problems. The values for the 5 photometers vary between $1.13^{\circ}$ and $1.32^{\circ}$, which means a discrepancy of $10 \%$ for the Cimel specified value of $1.2^{\circ}$.

The different periods of miscalibration are considered separately in photometer \#420. The value obtained does not depend on the pointing accuracy.

\subsection{Matrix measurements with a laser beam in the laboratory}

Here we present a second test for measuring the field of view using the matrix procedure. Instead of taking the Sun as a 


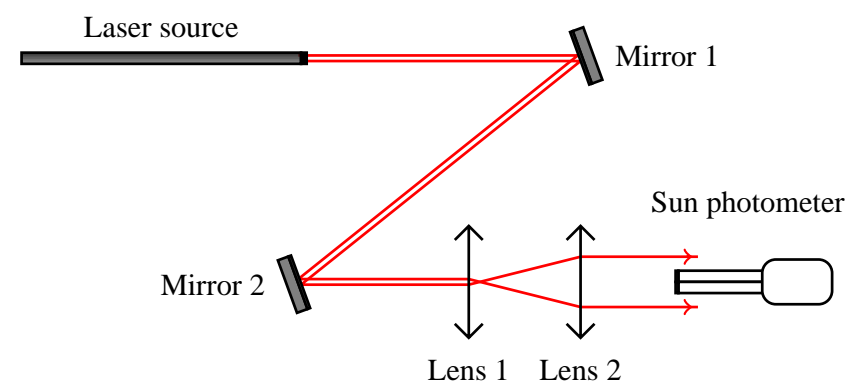

Fig. 13. Optic design to measure the FOV of Sun photometers with a laser beam.

source, we have used a laser beam in the laboratory which has been previously expanded and collimated in order to get an almost punctual source ${ }^{2}$ at infinity (see Fig. 13). We have introduced a spatial filter using an aperture of $12 \mu \mathrm{m}$ situated in the focal plane of the microscope objective lens (lens 1 in Fig. 13 with $f=16 \mathrm{~mm}$ ). The collimator lens had a focal length of $30 \mathrm{~cm}$, producing an expanding relation of about $1: 20$. After the beam is expanded, only the part limited by the entrance pupil of the photometer, which has a diameter around $5 \mathrm{~mm}$, is used. Consequently, with both systems, expander and optical filter, the uniformity of the beam is guaranteed as well as the absence of coherence noise (speckle).

The utilization of a punctual source results not only in the value of the field of view (following the methodology given by Nakajima et al., 1996, and summarized in Eq. 14) but also with the opportunity to estimate the shape of the response of the field of view in the Sun photometer.

Figure 14 shows an example of a matrix measurement in photometer \#143 using the laser beam in the laboratory. We can observe that the response of the field of view is practically cylindrical and that the fall is straight, indicating that in the optical system of the Sun photometer the limit illumination and full illumination are the same.

Comparing this representation with the one obtained in Fig. 7 where the Sun was used as the source, we see that in that case the fall was softer due to the angular size of the Sun.

The experiences with the laser beam are quite recent and we have only measured three photometers: \#143, \#353 and $\# 420$. The result of the tests are in accordance with those obtained in the field (using the Sun as a source) with differences under $5 \%$ as shown in Table 7. The FOV calculations from the vicarious method are also represented in Table 7, and the results agree better than $3 \%$ with respect to the other technique for both light sources.

\footnotetext{
${ }^{2}$ The angular size of any source can be estimated as the quotient between the size of the source, in this case $12 \mu \mathrm{m}$, and the focal length of the lens, which was $30 \mathrm{~cm}$ in the one used. With these data the angular size was about $0.0023^{\circ}$ in our experiments.
}

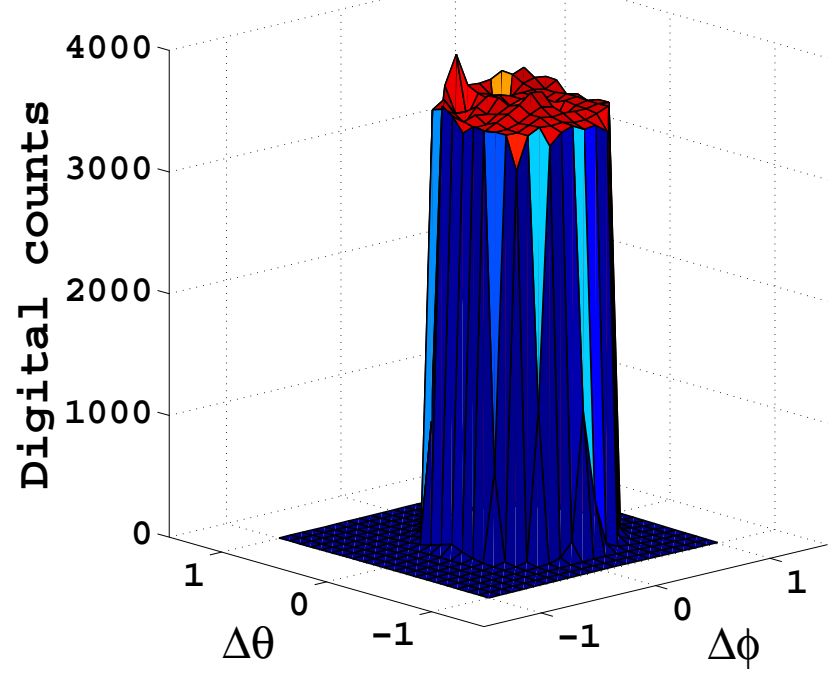

Fig. 14. Example of a matrix measurement using a laser beam with photometer \#143

Table 7. Comparison of the field of view results (given in degrees) obtained using the Sun and a laser beam as a source.

\begin{tabular}{cccc}
\hline Photo. & Sun & Laser & Vicarious \\
\hline$\# 353$ & 1.30 & 1.30 & 1.30 \\
$\# 143$ & 1.14 & 1.19 & 1.17 \\
$\# 420$ & 1.32 & 1.29 & 1.31 \\
\hline
\end{tabular}

\section{Discussion}

As commented in the Introduction, the work of Dubovik et al. (2000) concludes that a possible error in the azimuth angle during the pointing process is critical for the characterization of desert dust aerosol. The study was done simulating only almucantar measurements and considering $1^{\circ}$ as a pointing error. After the tests shown here, such a value for the pointing error is unrealistic and an update to this work should be done considering the results obtained here.

In the work of Torres (2012), almucantar and principal plane measurements are simulated and inverted, afterwards, introducing vertical and horizontal pointing errors $\left(\Theta_{\xi_{\theta}}=\xi_{\theta}\right.$ and $\Theta_{\xi_{\varphi}}=\sin \theta_{\mathrm{s}} \xi_{\varphi}$, respectively) of values $0.2^{\circ}, 0.4^{\circ}$ and $1^{\circ}$. Four aerosol types were considered: desert dust, maritime, urban and biomass burning. One of the main results of the analysis was that an error of $0.2^{\circ}$ does not produce relevant differences in the retrievals for almucantar simulations for both horizontal and vertical errors. However, slight differences can be seen for the principal plane, although only for vertical pointing errors in the four analyzed cases. 
The analysis of the extreme case $\mathrm{e}^{3}$ of $0.4^{\circ}$ (also described in Torres et al., 2013) shows that this value of the pointing error produces differences between $15 \%$ and $20 \%$ in the size distribution retrievals using principal plane geometry. The differences in the almucantar simulations are significantly smaller: around $10 \%$. This type of error also produces variations in the optical parameters: thus, absolute errors up to 0.02 are found in the retrievals of the single scattering albedo for both geometries. Finally, we want to indicate that horizontal errors did not introduce any variations for both geometries.

According to the results presented here, the typical pointing errors found in AERONET photometers stay within the range of tolerated uncertainties and would have no significant impact on the inversion-derived products. However in some cases larger errors have been detected that would yield biased retrievals, especially in the case of vertical error in the principal plane geometry. Therefore the monitoring of the pointing performance in the case of Sun/sky radiometers shows up as a necessary task to maintain the data quality.

\section{Conclusions}

The pointing error of the Cimel-318 Sun photometer has been determined through the use of two new measurement procedures: cross and matrix. However, the raw data produced by these new measurements have been shown to be insufficient for a correct evaluation of the pointing error, and a correction to account for Sun movement during the measurement had to be implemented.

The methodology proposed in this work was applied to several Sun photometers in a preliminary study. The results revealed that both measurement procedures, cross and matrix, are equivalent, with differences in the evaluation of the pointing error below $0.01^{\circ}$. For this reason, and due to the large amount of memory that is needed to record the data of matrix measurements, only the cross procedure has been integrated as part of the AERONET standard protocol for field measurements.

The analysis of the first results has indicated that, in general, the value of the pointing error in AERONET Sun photometers is smaller than $0.1^{\circ}$, though in some instruments values up to $0.3^{\circ}$ have been registered. Moreover, the pointing error has been shown to have a stable behavior over time and is not dependent on the solar zenith angle. These features can be used to detect other problems during the measurement process, such as mechanical malfunction in the robots or dirtiness in the 4-quadrant detector.

Using the matrix procedure, the field of view of five Sun photometers has been characterized obtaining values

\footnotetext{
${ }^{3}$ For most of the photometers with a field of view of $1.2^{\circ}$ this extreme value would be $0.35^{\circ}$ pointing error. However, the fact that some photometers analyzed here presented a value of the field of view around $1.3^{\circ}$ motivates us to enlarge the threshold up to $0.4^{\circ}$.
}

between $1.13^{\circ}$ and $1.32^{\circ}$. The maximum discrepancy with respect to the Cimel specification $\left(1.2^{\circ}\right)$ was $10 \%$. To verify this technique, a second test in the laboratory has been applied on three Sun photometers using a laser beam as a punctual source. The results of these tests are in accordance with those obtained using the Sun as a source with differences under $5 \%$. The use of the laser beam has also allowed us to certify that the shape of the response of the field of view is practically cylindrical, indicating that in the optical system of the Sun photometer, the limit illumination and the full illumination are the same.

Finally, the field of view of the same three Sun photometers have been also calculated using the so-called vicarious method. Differences under 3\% were found with respect to the other technique for both Sun and laser source.

Acknowledgements. We thank the AERONET, PHOTONS, RIMA and WRC staff for their scientific and technical support. Financial support was provided by the Spanish CICYT (CGL2009-09740 and CGL2011-23413, CGL2011-13085-E). The research leading to these results has received funding from the European Union Seventh Framework Programme (FP7/2007-2013) under grant agreement no. 262254 [ACTRIS]. We also thank the Environmental Council of the CyL Regional Government (Consejería de Medio Ambiente, Junta de Castilla y León) for supporting this research.

Edited by: M. King

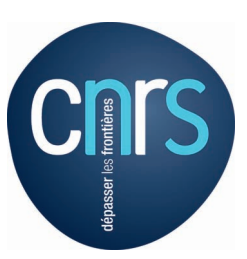

The publication of this article is financed by CNRS-INSU.

\section{References}

Dubovik, O. and King, M.: A flexible inversion algorithm for retrieval of aerosol optical properties from Sun and sky radiance measurements, J. Geophys. Res. Atmos., 105, 20673-20696, doi:10.1029/2000JD900282, 2000.

Dubovik, O., Smirnov, A., Holben, B., King, M., Kaufman, Y., Eck, T., and Slutsker, I.: Accuracy assessments of aerosol optical properties retrieved from Aerosol Robotic Network (AERONET) Sun and sky radiance measurements, J. Geophys. Res. Atmos., 105, 9791-9806, doi:10.1029/2000JD900040, 2000.

Dubovik, O., Holben, B., Eck, T., Smirnov, A., Kaufman, Y., King, M., Tanre, D., and Slutsker, I.: Variability of absorption and optical properties of key aerosol types observed in worldwide locations, J. Atmos. Sci., 59, 590-608, doi:10.1175/15200469(2002)059<0590:VOAAOP>2.0.CO;2, 2002.

Dubovik, O., Sinyuk, A., Lapyonok, T., Holben, B. N., Mishchenko, M., Yang, P., Eck, T., Volten, H., Munoz, O., Veihelmann, B., Van Der Zande, W. J., Leon, J., Sorokin, M., and Slutsker, I.: Application of spheroid models to account for aerosol particle nonsphericity in remote sensing of desert dust, J. Geophys. Res. Atmos., 111, doi:10.1029/2005JD006619, 2006. 
Holben, B., Eck, T., Slutsker, I., Tanre, D., Buis, J., Setzer, A., Vermote, E., Reagan, J., Kaufman, Y., Nakajima, T., Lavenu, F., Jankowiak, I., and Smirnov, A.: AERONET - A federated instrument network and data archive for aerosol characterization, Remote Sens. Environ., 66, 1-16, doi:10.1016/S00344257(98)00031-5, 1998.

Li, Z., Blarel, L., Podvin, T., Goloub, P., Buis, J.-P., and Morel, J.-P.: Transferring the calibration of direct solar irradiance to diffusesky radiance measurements for CIMEL Sun-sky radiometers, Appl. Opt., 47, 1368-1377, doi:10.1364/AO.47.001368, 2008.

Nakajima, T., Tanaka, M., and Yamauchi, T.: Retrieval of the optical-properties of aerosols from aureola and extinction data, Appl. Opt., 22, 2951-2959, 1983.

Nakajima, T., Tonna, G., Rao, R., Boi, P., Kaufman, Y., and Holben, B.: Use of sky brightness measurements from ground for remote sensing of particulate polydispersions, Appl. Opt., 35, 2672-2686, doi:10.1364/AO.35.002672, 1996.

Reda, I. and Andreas, A.: Solar position algorithm for solar radiation applications, Sol. Energy, 76, 577-589, doi:10.1016/j.solener.2007.01.003, 2004.

Sinyuk, A., Holben, B. N., Smirnov, A., Eck, T. F., Slutsker, I., Schafer, J. S., Giles, D. M., and Sorokin, M.: Assessment of error in aerosol optical depth measured by AERONET due to aerosol forward scattering, Geophys. Res. Lett., 39, L23806, doi:10.1029/2012GL053894, 2012.
Smirnov, A., Holben, B., Eck, T., Dubovik, O., and Slutsker, I.: Cloud-screening and quality control algorithms for the AERONET database, Remote Sens. Environ., 73, 337-349, doi:10.1016/S0034-4257(00)00109-7, 2000.

Torres, B.: Pointing errors in sky radiance measurements from sunphotometers. Influence on inversion-retrieved aerosol properties, Observations and modeling of aerosol and clouds properties for climate studies, Paris, France, 2011.

Torres, B.: Study on the influence of different error sources on sky radiance measurements and inversion-derived aerosol products in the frame of AERONET, Ph.D. thesis, Universidad de Valladolid, 2012.

Torres, B., Dubovik, O., Toledano, C., Berjon, A., Cachorro, V. E., Lapyonok, T., and Goloub, P.: Sensitivity of aerosol retrieval to geometrical configuration of ground-based sun/sky-radiometer observations, Atmos. Chem. Phys. Discuss., 13, 6851-6921, doi:10.5194/acpd-13-6851-2013, 2013.

Vermeulen, A.: Caractérisation des aérosols á partir de mesures optiques passives au sol: apport des luminances totale et polarisée mesurées dans le plan principal, Ph.D. thesis, Université de Lille, 1996. 